\title{
Dependence Structure between Conventional and Islamic Indexes: A Copula Approach
}

\author{
Samia Ben Messaoud \\ International Finance Group-Tunisia \\ Faculty of Economics and Management of Tunis \\ University of Tunis El Manar, Tunisia \\ E-mail: samia.benmessaoud@yahoo.fr \\ Mondher Kouki \\ Department of Accounting and Finance \\ Faculty of Management and Economics of Tunis \\ University of Tunis El Manar, Tunisia \\ E-mail: koukimondher@yahoo.fr
}

Received: July OI, 2020

doi: I0.4628I/ijibfr.v4i2.703
Accepted: July 20, 2020

Online Published: August 09, 2020

URL: https://doi.org/I0.4628I/ijibfr.v4i2.703

\begin{abstract}
This article examines the conditional dependence structure between Islamic stock indexes and conventional counterparts. Our empirical analysis relies on Islamic and conventional indexes of dependence distribution using copula methods over the period 1999-20I4. The results from the copula models denote that the dependence is not formally symmetric in that the lower tail dependence is significantly larger than the upper tail dependence.
\end{abstract}

Keywords: Asymmetric Dependence, Copula Models, Islamic Stock Indexes, Conventional, Counterparts

\section{Introduction}

With the beginning of the Islamic financial industry, many Islamic financial institutions (IFI's) are founded and based on a set of regulations referred to Islamic law. Among these rules, we must insist on the sharing of loss, profit, and risk. Interest and excessive uncertainty are forbidden. Also, the IFI's must avert the business with non-ethical sectors. With the consideration of moral, social dimensions, and religious principles, the work of (Arouri, Ben Ameur, Jawadi, Jawadi, \& Louhichi, 2013) shows that the Islamic financial system is more stable than the ordinary system, particularly during the crisis period.

In the last decade, the financial sector admits that Islamic banking is rapidly growing. While the advocates of Islamic system advertise its ability to promote justice, some works (Jobst, 2007; Khan, 2010), showed the distinction between the ideals and the practices of IFI's.

With the interdiction of interest, Islamic finance is based on the equity markets. Hence, IFI's are seeking for-profit earned from their portfolio. The surge of the Islamic capital market gives some innovations in terms of risk management and product. We can cite the innovation by launching of Shariah-compliant indices. These indices asserted that these indices are similar to social indices in terms of screening for avoiding the violations of legal prohibition, but the main difference between them is that the referent is religious for Islamic indices (El-Gamal, 2006; Ghoul \& Karam, 2007). So, this investigate uses an indication of nine regional stock Islamic indexes including the United States large, the United States mid and United States small, U.K, Canada, Japan, Europe, Asia- and the World, and their conventional counterparts

The paper is organized as follows. First, we present the view of the state-of-the-art empirical method (Section 2) and then move to a complete description of the proposed model and data in our experimental setup (Section 3). In Section 4, we give a presentation of the results and we discuss the findings and finally provide a conclusion (Section 5). 


\section{Literature Review}

In April 1998, Dar al-Mal al-Islami and Faisal Finance Bank have launched the index DMI I50 to follow the performance of I50 publicly traded companies. In November 1998, a Socially Aware Muslim Index was produced to measure the performance of 500 Shariah-compliant companies. In February 1999, the Dow Jones Islamic Market Index has launched and in October 1999, Global Islamic Index Series (GIIS) is created at the London Stock Exchange. After this beginning, many markets had started their Islamic indices such as MSCI Barra in March 2007 and the Dow Jones Islamic Market Index in February I999. Also, some financial markets in Asia and Africa have created their Islamic indices with a local focus.

The indices track a common stock selection process named stock screening with the maintenance of Shariah principles in the screening process. The Shariah boards possess two steps of screening process. The first stage of the screening consists to exclude firms operating in specific activities. The problem occurs when the business of the firm is legal but fraught with some illegal transactions (Yaquby, 2000; El-Gamal, 2006).

The second stage of screening concerns quantitative screens based on financial ratios. The ratios have developed when Islamic institutions have included, in their portfolios stocks, some companies with illegal income and small amounts of interest and (El-Gamal, 2006). However, the methodology applied is not the same for all Sharia boards then the Islamic indices have not obtained a high level of scrutiny (Fowler \& Hope, 2007; Derigs \& Marzban, 2008).

In our paper show the absence of co-integration for Dow Jones Islamic Market Index but his presence in MSCI and FTSE the indices. Also, we test the efficiency of the indices. The experiments of our paper show that both conventional and Islamic indices have the same level of effectiveness.

\section{Empirical Method}

The objective of this part is to present the theoretical foundations then to define the multivariate distributions and the important property of the uniform law, then we present the concept of copula through examples that we will use.

\section{I Properties}

Sklar's Theorem

The Sklar's Theorem determines the link defined by copula C, determined through the joint distribution F, between bivariate complete distribution $\mathrm{F}$ and univariate marginal distribution functions FI and F2.

The theorem: suppose F a bivariate distribution with margins FI and F2. The copula C associated with F is written:

$$
\begin{aligned}
& C\left(u_{1}, \ldots \ldots \ldots, u_{d}\right)=C\left(F_{1}\left(x_{1}\right), F_{2}\left(x_{2}\right), \ldots \ldots \ldots . ., F_{d}\left(x_{d}\right)\right) \\
& =F\left(F_{1}^{-1}\left(x_{1}\right), F_{2}^{-1}\left(x_{2}\right), \ldots \ldots \ldots, F_{d}^{-1}\left(x_{d}\right)\right) \\
& =F\left(x_{1}, x_{2}, \ldots \ldots, x_{d}\right)
\end{aligned}
$$

$\mathrm{C}$ is unique when the margins $\mathrm{FI}$ and $\mathrm{F} 2$ are continuous.

The density $\mathrm{F}$ is presented as a function of density c:

$$
\mathrm{F}\left(x_{1}, x_{2}, \ldots \ldots, x_{d}\right)=\mathrm{C}\left(F_{1}\left(x_{1}\right), F_{2}\left(x_{2}\right), \ldots \ldots F_{d}\left(x_{d}\right)\right)
$$

\subsection{Tail Dependence}

Tail dependence is defined as a bivariate copula. It measures simultaneous extreme occurrence probability.

Tail dependence index of a copula is reduced to the following conditional probabilities:

$$
\begin{aligned}
& P\left[U_{1} \leq u_{1} / U_{2} \leq u_{2}\right]=\frac{P\left[U_{1} \leq u_{1}, U_{2} \leq u_{2}\right]}{P\left[U_{2} \leq u_{2}\right]}=\frac{C\left(u_{1}, u_{2}\right)}{u_{2}} \\
& P\left[U_{1}>u_{1} / U_{2}>u_{2}\right]=\frac{P\left[U_{1}>u_{1}, U_{2}>u_{2}\right]}{P\left[U_{2}>u_{2}\right]}=\frac{P\left[U_{1} \leq 1, U_{2}>u_{2}\right]-P\left[U_{1} \leq u_{1}, U_{2}>u_{2}\right]}{P\left[U_{2} \leq 1\right]-P\left[U_{2} \leq u_{2}\right]} \\
& =\frac{1-u_{1}-u_{2}+C\left(u_{1}, u_{2}\right)}{1-u_{2}}
\end{aligned}
$$


Then we can define lower and upper tail dependence.

A copula C has lower tail dependence if:

$$
\lambda_{L}=\lim _{u \rightarrow 0^{+}} \frac{C(u, u)}{u}
$$

Then the copula $C$ has an lower tail dependence if $\lambda_{L} \epsilon(0, I]$, if $\lambda_{L}=0$ there is no lower tail dependence.

A copula $C$ has an upper tail dependence if:

$$
\lambda_{u}=\lim _{u \rightarrow 1^{-}} \frac{1-2 u+C(u, u)}{1-u}
$$

Then the copula $C$ has an upper tail dependence if $\lambda_{L} \in(0, I]$, if $\lambda_{L}=0$ there is no upper tail dependence.

\subsection{The Copula Model}

3.3.I Gaussian Copula

The Gaussian copula is defined as follows:

$$
C_{\rho}(u, v)=\Phi_{p}\left(\phi^{-1}(u), \phi^{-1}(v)\right)
$$

$\phi:$ a Normal distribution function $\mathrm{N}(\mathrm{O}, \mathrm{I})$;

$\Phi_{p}:$ Distribution of the centered Gaussian vector $(\mathrm{X} ; \mathrm{Y})$ of the covariance matrix $\left(\begin{array}{ll}1 & \rho \\ \rho & 1\end{array}\right)$

$$
\Phi_{p}=\int_{-\infty}^{x} \int_{-\infty}^{y} \frac{1}{2 \pi \sqrt{\left(1-\rho^{2}\right)}} \exp \left[-\frac{\left(s^{2}+t^{2}-2 \rho s t\right)}{2\left(1-\rho^{2}\right)}\right] d s d t
$$

Even if correlations of ranks are better to analyze a joint distribution of financial data than linear correlations, there is a match between a linear correlation coefficient p, Kendall's Tau T and Spearman Rho Q. Kendall's Tau is written as follows:

$$
\tau_{k}=\frac{2}{\pi} \arcsin \rho
$$

Spearman Rho is written as follows:

$$
v_{s}=\frac{6}{\pi} \arcsin \frac{\rho}{2}
$$

\subsubsection{Student Copula}

Student copula is defined as follows:

$$
\begin{aligned}
& C\left(u_{1}, u_{2} ; \rho, k\right)=T_{\rho, k}\left(T_{k}^{-1}\left(u_{1}\right), T_{k}^{-1}\left(u_{2}\right)\right) \\
& t_{\rho, v}(x, y)=\int_{-\infty}^{x} \int_{-\infty}^{y} \frac{1}{2 \pi \sqrt{1-\rho^{2}}}\left(1+\frac{s^{2}+t^{2}-2 \rho s t}{v\left(1-\rho^{2}\right)}\right)^{-\frac{v+2}{2}} d s d t
\end{aligned}
$$


Also, we apply the same relationship of Kendall's Tau for a Gaussian copula.

$$
\tau_{k}=\frac{2}{\pi} \arcsin \rho
$$

\subsubsection{Archimedean Copulas}

An Archimedean copula is defined as follows:

$$
c_{\rho, v}(u, v)=\varphi^{-1}\{\varphi(u)+\varphi(v)\}, 0<u, v<1
$$

To measure dependence between different financial markets, we use the three types of Archimedean copula functions Patton (2003).

Clayton Copula:

$$
C_{\theta}(u, v)=\left(u^{-\theta}+v^{-\theta}-1\right)^{-1 / \theta}
$$

Generator:

$$
\phi(x)=\frac{u^{-\theta}-1}{\theta}
$$

Gumbel Copula:

$$
C_{\theta}(u, v)=\exp \left[-\left((-\ln u)^{\theta}+(-\ln v)^{\theta}\right)^{1 / \theta}\right]
$$

Generator:

$$
\phi(x)=(-\ln u)^{\theta}
$$

Frank Copula

$$
C_{\theta}(u, v)=-\frac{1}{\theta} \ln \left[1+\frac{\left(e^{-\theta u}-1\right)\left(e^{-\theta v}-1\right)}{e^{-\theta}-1}\right]
$$

Generator:

$$
\phi(x)=-\ln \left(\frac{e^{-\theta u}-1}{e^{-\theta}-1}\right)
$$

Kendall's tau is equal for Archimedean Copulas:

$$
c_{\rho, v}(u, v)=\varphi^{-1}\{\varphi(u)+\varphi(v)\}, 0<u, v<1
$$




\subsubsection{Symmetrized Joe-Clayton Copula}

$$
\begin{gathered}
C_{S J C}\left(\mu, v / \tau_{U}, \tau_{L}\right)=1-\left(\left\{\left[1-(1-\mu)^{\kappa}\right]^{-\gamma}+\left[1-(1-v)^{\kappa}\right]^{-\gamma}-1\right\}^{-1 / \gamma}\right)^{1 / \kappa} \\
\kappa=1 / \log _{2}\left(2-\tau_{U}\right) \\
\gamma=-1 / \log _{2}\left(\tau_{L}\right) \\
\tau_{U} \in(0,1), \tau_{L} \in(0,1)
\end{gathered}
$$

In Joe-Clayton copula, we use two parameters $\tau_{U}$ and $\tau_{L}$, which are the coefficients of low and upper tail dependence. When $\tau_{U}=\tau_{L}$ we obtain a slight asymmetry copula. to overcome this problem,

$$
C_{S . J C}\left(\mu, v / \tau_{U}, \tau_{L}\right)=0.5 C_{S . J C}\left(\mu, v / \tau_{U}, \tau_{L}\right)+0.5 C_{S . J C}\left(1-\mu, 1-v / \tau_{U}, \tau_{L}\right)+\mu+v-1
$$

In this case when $\tau_{U}=\tau_{L}$, we obtain a symmetric copula.

\section{Data and Method}

The daily Islamic and conventional indexes cover six countries (Eurozone, UK, Japan, Asia-Pacific, Canada and The United States. These are of the conventional and Islamic indexes. Also, we use conventional stock and the World Islamic indexes. The nine indexes and sub-indexes DJI Europe, DJI UK, DJI Japan, DJI Asia-Pacific, DJI Canada, DJI US large Cap., DJI US midCap., and DJI US small Cap are used in our method for evaluation and correspond to both the Dow Jones Islamic Market (hereafter, DJIM) index and the conventional index (hereafter, DJI) cover the period January I I990 to June 20I4. We run a rolling window of I0-daily volatility observations to examine the volatility spillover patterns between the Islamic indexes and conventional.

The US monthly Islamic is employed in this study and conventional equity indexes over the period, 1990:4 to

\begin{tabular}{|c|c|c|c|c|c|c|c|c|c|}
\hline & $\begin{array}{l}\text { DJIM } \\
\text { Asia }\end{array}$ & $\begin{array}{l}\text { DJIM } \\
\text { US large }\end{array}$ & $\begin{array}{l}\text { DJIM } \\
\text { US Mid }\end{array}$ & $\begin{array}{l}\text { DJIM } \\
\text { US } \\
\text { small }\end{array}$ & $\begin{array}{l}\text { DJIM } \\
\text { Europe }\end{array}$ & $\begin{array}{l}\text { DJIM } \\
\text { Canada }\end{array}$ & $\begin{array}{l}\text { DJIM } \\
\text { World }\end{array}$ & $\begin{array}{l}\text { DJIM } \\
\text { Japan }\end{array}$ & $\begin{array}{c}\text { DJIM } \\
\text { US }\end{array}$ \\
\hline $\begin{array}{l}\text { Mean returns } \\
(\%)\end{array}$ & 0.0002 & $\begin{array}{l}0.0001- \\
-\end{array}$ & $0.000 \mathrm{I}$ & 0.0003 & 0.0001 & 0.0002 & $0.000 \mathrm{I}$ & $0.000 \mathrm{I}$ & 0.00017 \\
\hline Std. dev. & 0.0126 & 0.0126 & 0.0152 & 0.0159 & 0.0161 & 0.0187 & 0.0108 & 0.0145 & 0.0129 \\
\hline Kurtosis & 7.9033 & 10.467 & 7.7752 & $6.3 \mathrm{I} 3 \mathrm{I}$ & 8.7078 & $\mathrm{I} 2.6486$ & 9.8299 & 6.3632 & 9.7239 \\
\hline Jarque-Bera & 4089.3 & 9189.3 & 3800.75 & 1834.66 & 5369.36 & I577I.3 & $7748.9 \mathrm{I}$ & 1890.6 & 7452.46 \\
\hline p-values & $(0.000)$ & $(0.000)$ & $(0.000)$ & $(0.000)$ & $(0.000)$ & $(0.000)$ & $(0.000)$ & $(0.000)$ & $(0.000)$ \\
\hline $\begin{array}{l}\operatorname{AR}(\mathrm{I}) \\
\text { coefficient }\end{array}$ & 0.0566 & $0.067^{\text {th }}$ & $0.0452^{\text {*x }}$ & $0.0458^{\text {* }}$ & $0.024^{\text {sax }}$ & $0.066^{x}$ & $0.026^{x}$ & $0.183^{\text {犁 }}$ & $0.07 I$ \\
\hline
\end{tabular}
2010:I2. We take the monthly returns from DataStream and measure the difference in the logarithm of the ratio of two successive prices. From Baker and Wurgler (2007), we have obtained the United States investors' sentiment indexes. The descriptive statistics verify the series are described in tableI and table 2 .

Table I . Summary statistics of market returns Daily Islamic index 
Table 2. Summary statistics of market returns daily conventional

\begin{tabular}{|c|c|c|c|c|c|c|c|c|c|}
\hline & DJI Asia & $\begin{array}{l}\text { DJI } \\
\text { US } \\
\text { large } \\
\end{array}$ & $\begin{array}{l}\text { DJI } \\
\text { US mid }\end{array}$ & $\begin{array}{l}\text { DJI US } \\
\text { small }\end{array}$ & $\begin{array}{l}\text { DJI } \\
\text { Europe }\end{array}$ & $\begin{array}{l}\text { DJI } \\
\text { Canada }\end{array}$ & DJI World & DJI Japan & DJI US \\
\hline Mean returns & 0.0002 & 0.0001 & 0.0003 & 0.0002 & $0.000 \mathrm{I}$ & 0.00033 & 0.0001 & 0.0001 & 0.0001 \\
\hline Skewness & -0.4254 & -0.1893 & $-0.4 \mathrm{I} 7$ & -0.29 & $-0.04 \mathrm{I}$ & -0.7213 & -0.365 & -0.20 & -0.23 \\
\hline Kurtosis & 9.467 & 10.467 & 9.467 & 9.467 & 10.467 & 9.467 & 9.467 & 9.46 & 9.46 \\
\hline JarqueBera & 4039.6 & 10368 & 7383.0 & 2778.7 & 4244.6 & 14697. & 8338.68 & 2485.9 & 9393.6 \\
\hline p-values & $(0.000)$ & $(0.000)$ & $(0.000)$ & $(0.000)$ & $(0.000)$ & $(0.000)$ & $(0.000)$ & $(0.000)$ & $(0.000)$ \\
\hline $\begin{array}{l}\operatorname{AR}(\mathrm{I}) \\
\text { coefficient }\end{array}$ & $0.0183^{\text {th }}$ & 0.0677 & $0.054 I^{\text {x }}$ & $0.040 I^{\not x}$ & $0.024^{x}$ & 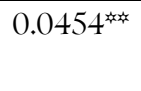 & $0.0642^{\text {到 }}$ & $0.0524^{\text {* }}$ & $0.07 I^{\text {tx }}$ \\
\hline Observations & 3955 & 3955 & 3955 & 3955 & 3955 & 3955 & 3955 & 3955 & 3955 \\
\hline
\end{tabular}

In table I, we show that all the data series are negatively skewed which indicates that the returns are not normally distributed. To estimate the distribution and stochastic properties of US monthly Islamic (i.e. The Dow Jones Islamic index) and conventional equity indexes, primary we noticed into some descriptive statistics on the returns of the countries presented in table 2. The statistics prove that all returns series are negatively biased and display excessive kurtosis. This indicates that returns are not normally distributed.

\section{Results and Discussion}

In this section, we present the results of the various copula models used to investigate the dependence patterns among 8 pairs of stock returns representing seven stock markets/indices from the GCC region. First, we present estimated coefficients for the Gaussian copula, Student's t-copula, and the symmetrized Joe-Clayton copula for 8 combinations of pairs comprising returns of US monthly Islamic and conventional equity indexes. For all pairs, the dependence parameters in the t-copula, the upper and lower tail dependence parameters in the SJC copulas are positive and strongly significant.

The correlation coefficient estimates from the Gaussian copulas range from 0.I838 to 0.985, while those from the Student's t-copula model range from 0.I422 to 0.907. These estimated parameters are very close to the linear correlation coefficients from the data as shown in Table 3. It also suggests that Gaussian copula which does not allow for tail dependence, is not sufficient in modeling the dependence of the stock indices pairs. The estimated tail dependence coefficients indicate that, for 8 pairs, the extent of $\lambda_{u}$ is always higher than that of $\lambda_{u}$, implying that there is substantially higher dependence in the lower tail of the distribution (negative extremes) than in the higher tail (positive extremes). According to Longin and Solnik (200I), when the correlation on the left tail is much more than the correlation on the right tail, a bear market state, rather than volatility, is the driving force increasing dependence across international equity markets. Our findings corroborate their proposition. Moreover, this observation suggests that the dependence structure is not symmetric since symmetry implies that the difference $\left(\lambda_{\mathrm{L}}-\right.$ $\lambda_{\mathrm{u}}$ ) should be zero.

Table 3. Estimation of the joint copula parameters and tail dependence (US monthly Islamic and conventional equity indexes)

\begin{tabular}{|c|c|c|c|c|c|c|}
\hline \multirow[t]{2}{*}{ Parameters } & $\begin{array}{l}\text { Gaussian } \\
\text { copula }\end{array}$ & t-copula & $\begin{array}{l}\text { Symmetric Joe } \\
\text { Clayton } \\
\text { Copula }\end{array}$ & $\begin{array}{l}\text { Gaussian } \\
\text { copula }\end{array}$ & t-copula & $\begin{array}{l}\text { Symmetric } \\
\text { Joe Clayton } \\
\text { Copula }\end{array}$ \\
\hline & \multicolumn{3}{|c|}{ DJIM Asia_DJI Asia } & \multicolumn{3}{|c|}{ DJIM US small _ DJI US small } \\
\hline$\rho$ & 0.18 & 0.1422 & & 0.985 & & \\
\hline$\lambda_{U}$ & & & 0.036 & & & 0.82 \\
\hline$\lambda_{L}$ & & & 0.095 & & & 0.83 \\
\hline AIC & -136.07 & -210.57 & -209.24 & $-\mathrm{I} 4 \mathrm{I} .407$ & $-\mathrm{I} 46.4$ & $-\mathrm{I} 05.25$ \\
\hline $\mathrm{BIC}$ & -136.07 & -210.567 & -209.244 & $-\mathrm{I} 4 \mathrm{I} .407$ & -146.4 & -105.25 \\
\hline LL & -98.03 & -108.976 & -104.785 & -137.919 & -453.10 & -102.95 \\
\hline
\end{tabular}




\begin{tabular}{cllllll}
\hline Parameters & $\begin{array}{l}\text { Gaussian } \\
\text { copula }\end{array}$ & t-copula & $\begin{array}{l}\text { Symmetric } \\
\text { Joe Clayton } \\
\text { Copula }\end{array}$ & Gaussian copula & t-copula & $\begin{array}{l}\text { Symmetric Joe } \\
\text { Clayton } \\
\text { Copula }\end{array}$ \\
\cline { 2 - 6 } & DJIM US Mid_DJI US Mid & DJIM US Large_DJI US Large \\
\hline$\rho$ & 0.9609 & 0.893 & 0.849 & 0.9679 & 0.90 & \\
\hline$\lambda_{U}$ & & 0.814 & & 0.829 \\
\hline$\lambda_{L}$ & & & & -953 & -105.25 \\
\hline AIC & -101.602 & -103.125 & -99.414 & -109.358 & -105.25 \\
\hline BIC & -101.602 & -103.125 & -99.411 & -109.358 & -95.06 & \\
\hline LL & -98.1203 & -100.120 & -92.009 & -101.919 & -91.10 & -102.95 \\
\hline
\end{tabular}

With our method, The DJIM Islamic index and DJI conventional index obtains the highest upper and lower tail dependence. We can conclude that the dynamics of response to a shock is lower regional counterparts than in these markets. In the case of asymmetry $\left(\left(\lambda_{\mathrm{L}}-\lambda_{\mathrm{u}}\right)>0\right.$, the dependence mainly concerns down-side risk co-movement in the lower tail of distribution but the gains are economically significant. We can explain the results by the fact that investors are more sensitive to bad news than good news in other markets (Hu, 2006).

Table 4. Estimation of the joint copula parameters and tail dependence (US monthly Islamic and conventional equity indexes)

\begin{tabular}{|c|c|c|c|c|c|c|}
\hline \multirow[t]{2}{*}{ Parameters } & $\begin{array}{l}\text { Gaussian } \\
\text { copula }\end{array}$ & t-copula & $\begin{array}{l}\text { Symmetric } \\
\text { Joe Clayton } \\
\text { Copula }\end{array}$ & $\begin{array}{l}\text { Gaussian } \\
\text { copula }\end{array}$ & t-copula & Symmetric Joe Clayton Copula \\
\hline & $\begin{array}{l}\text { DJIM } \\
\text { Japon_DJI } \\
\text { Japon }\end{array}$ & & & $\begin{array}{l}\text { DJIM } \\
\text { Canada_ } \\
\text { DJI } \\
\text { Canada }\end{array}$ & & \\
\hline$\rho$ & 0.183 & 0.1422 & 0.833 & 0.8472 & 0.8449 & \\
\hline$\lambda_{U}$ & & & 0.834 & & & 0.773 \\
\hline$\lambda_{L}$ & & -322.754 & & & & 0.8472 \\
\hline AIC & -322.754 & -209.570 & -133.777 & -80.552 & -80.552 & -105.255 \\
\hline $\mathrm{BIC}$ & -322.754 & -209.567 & -134.777 & -82.898 & -80.552 & -105.254 \\
\hline \multirow[t]{2}{*}{ Parameters } & $\begin{array}{l}\text { Gaussian } \\
\text { copula }\end{array}$ & t-copula & $\begin{array}{l}\text { Symmetric } \\
\text { Joe } \\
\text { Clayton } \\
\text { Copula }\end{array}$ & $\begin{array}{l}\text { Gaussian } \\
\text { copula }\end{array}$ & $\begin{array}{l}\text { Student } \\
\text { copula }\end{array}$ & Symmetric Joe Clayton Copula \\
\hline & DJIM euro & JI europe & & DJIM US & DJI US & \\
\hline$\rho$ & $0.96 \mathrm{I}$ & 0.887 & & $0.97 \mathrm{I}$ & 0.848 & \\
\hline$\lambda_{U}$ & & & 0.837 & & & 0.844 \\
\hline$\lambda_{L}$ & & & 0.846 & & & 0.834 \\
\hline$\overline{\mathrm{AIC}}$ & -102.336 & -222.754 & $-\mathrm{I} 33.777$ & $-\mathrm{II} 3.59 \mathrm{I}$ & $-\mathrm{II} 8.023$ & -108.903 \\
\hline BIC & $-\mathrm{I} 22.754$ & -200.647 & $-\mathrm{I} 33.777$ & $-\mathrm{II} 3.59 \mathrm{I}$ & - II 8.023 & -108.903 \\
\hline LL & -161.377 & -100.425 & $-6692.6 \mathrm{I}$ & -5679.56 & -5901.163 & $-5446.10 \mathrm{I}$ \\
\hline LL & -161.377 & -98.976 & -92.618 & $-414.9 \mathrm{II}$ & -407.615 & -520.956 \\
\hline
\end{tabular}


We note that conventional equity and US monthly Islamic indexes indicate correspond dependence structures between DJIM Japan_DJI Japan monthly Islamic and conventional equity indexes, as represented by the Gaussian copula. DJIM US large_DJI US large indicate the same dependence structures described by the Symmetric Joe- Clayton copula. The Student copula gives a better fit for DJIM US_DJIUS.

For example, the Clayton Symmetric Joe-Clayton parameter is larger in DJIM Canada_DJI Canada.

Table 3 presents predicted coefficients for the Gaussian copula, Student's t-copula and the summarized Joe-Clayton copula for 8 combinations of pairs comprising US Islamic and conventional indexes. For all pairs, the dependence, parameters (the correlation coefficient, in both Gaussian and t-copulas), t the t-copula, and the upper and lower Tail dependence parameters in the SJC copulas are positive and strongly significant.

Presents estimated coefficients for the Gaussian copula, Student's t-copula and the summarized Joe-Clayton copula for 8 combinations of pairs comprising returns of seven GCC stock indices. For all pairs, the dependence parameters, the upper and lower tail dependence parameters in the SJC copulas are positive and strongly significant. The parameter captures the tail dependence of t-copulas. For instance, the correlation coefficient estimates from the Gaussian copulas range from 0.183 to 0.97I, while those from the Student's t-copula model range from 0.I42I to 0.907. It also suggests that Gaussian copula which does not allow for tail dependence, is not sufficient in modeling the dependence of the stock indices pairs. The estimated tail dependence coefficients indicate that, for 20 out of 8 pairs, the extent of $\lambda_{L}$ always higher than that of $\lambda_{u}$, denote that there is essentially higher dependence in the lower tail of the distribution (negative extremes) than in the higher tail (positive extremes). According to Longin and Solnik (200I), the correlation on the left tail is frequently than the correlation on the right tail, rather than volatility, is the compelling make growing dependence using international equity markets. Our returns confirm their suggestion. Besides, this study proposes that the dependence structure is not proportional since symmetry implies that the difference $\lambda_{\mathrm{L}}-\lambda_{\mathrm{u}}$ should be zero.

\section{Conclusion}

Islamic indices can give the occasion to investing in the equity market by the investors according to their ethical commitment. This work, we essay to analyze some indices and see if they offer an opportunity for portfolio diversification or not and examine if they have the same efficiency level as their conventional counterparts or not. In our work, we analyze and test of conventional and Islamic indices. Also, we study the power and effectiveness level of Islamic indices in comparison with their conventional benchmarks. So, we explore the co-integration of Islamic indices provided Standard \& Poors, Poor and MSCI. In experiments, we show the nonappearance of co-integration among the Standard and Poors, Poor and Dow Jones index families. We can conclude the presence of diversification opportunities for the two indices. However, the FTSE and MSCI indices are cointegrated. Hence, we deduce the existence of a theoretical relationship among the indices and the absence of diversification opportunities. Additionally, we can conduct that both conventional and Islamic indices have the same level of effectiveness. However, MSCI and FTSE indices are the most efficient.

We conclude that the market-capitalization based Shariah screening requirements give absence of co-integration and higher efficiency in the case of S\&P and Dow Jones indices and the presence of co-integration and less efficiency in the case of MSCI and FTSE indices. Conventional and Islamic indices have similar long-run diversification benefits. The co-integration and the efficiency of Islamic indices may have an impact on portfolio diversification by the managers and maximize the risk-adjusted returns of investors without compromising their beliefs. To enhance efficiency, the Shariah boards could improve the transparency level for Islamic equity indices.

As future work, we must study the Islamic sub-indices of each Islamic index family.

\section{References}

Arouri, M. E., Ben Ameur, H., Jawadi, N., Jawadi, F., \& Louhichi, W. (2013). Are Islamic finance innovations enough for investors to escape from a financial downturn? Further evidence from portfolio simulations. Applied Economics, $45(24), 3412-3420$.

Baker, M. and Jeffrey, W. (2007). Investor sentiment in the stock market. Journal of Economic Perspectives, 2I(2), I29-5I.

Derigs, U. and Marzban, S. (2008). Review and analysis of current Shariah-compliant equity screening practices. International Journal of Islamic and Middle Eastern Finance and Management, I (4), 285-303.

El-Gamal, M. (2003). Interest and the Paradox of Contemporary Islamic Law and Finance, Fordham International Law Journal, $27(\mathrm{I})$, I08-I49.

El-Gamal, M.A. (2006). Islamic Finance: Law, Economics and Practice, Cambridge University Press, New York City.

Fowler, S.J., and Hope, C.A. (2007). Critical Review of Sustainable Business Indices and their Impact. Joumal of Business Ethics, $76(3), 243-252$.

Ghoul, W., and Karam, P. (2007). MRI and SRI mutual funds: A comparison of Christian, Islamic (morally responsible investing), and socially responsible investing (SRI) mutual funds. Journal of Investing I6(2), 96-I02. 
Hu, Y. (2006). The impact of pension funds on financial markets. Financial Market Trends (2006) 2. Paris: OECD.

Jobst, A. (2007). The Economics of Islamic Finance and Securitization, Document du Fonds Monétaire International, 36 (I2). I82-I83.

Khan, F. (2010). How Islamic is Islamic banking?, Journal of Economic Behavior \& Organization 76(3), 805- 820.

Longin, F. Solnik, B. (200I). Extreme correlation of international equity markets, Journal Finance, 56(2), 649-676.

Patton, A. (2003). Modeling asymmetric exchange rate dependence. Working paper, University of California, San Diego.

Yaquby, N. (2000). Participation and Trading in Equities of Companies whose Main Business is Primarily Lawful but Fraught with some Prohibited Transactions. Paper presented to the Fourth Harvard Islamic Finance Forum, October 2000.

\section{Copyrights}

Copyright for this article is retained by the author(s), with first publication rights granted to the journal. This is an open-access article distributed under the terms and conditions of the Creative Commons Attribution license (http://creativecommons.org/licenses/by/4.0/). 